\title{
Análise Sobre o Acesso aos Programas de Políticas Públicas da Agricultura Familiar nos Municípios do Circuito das Frutas (SP) ${ }^{1}$
}

\author{
Vanilde Ferreira de Souza-Esquerdo² e \\ Sonia Maria Pessoa Pereira Bergamasco ${ }^{3}$
}

Resumo: Com o reconhecimento da agricultura familiar brasileira enquanto categoria social e produtiva a partir dos anos 90, diversos programas de políticas públicas foram formulados no sentido de garantir sua reprodução enquanto produtora de alimentos básicos para a alimentação, além da manutenção e ocupação do homem no campo. Diante disto, este texto tem como principal objetivo analisar a agricultura familiar nos municípios do chamado "Circuito das Frutas" do estado de São Paulo em relação à importância ao acesso aos principais programas de políticas públicas que visam o fortalecimento desta agricultura. Uma vez que esta região se caracteriza pela presença marcante de agricultores familiares, foram analisados o Pronaf (Programa Nacional de Fortalecimento da Agricultura Familiar), o PAA (Programa de Aquisição de Alimentos) e o PNAE (Programa Nacional de Alimentação Escolar), programas que têm se constituído em instrumentos de valorização deste segmento da agricultura paulista. Percebeu-se que, diante do universo da agricultura familiar nos municípios estudados, ainda é pequena a participação dos mesmos nos programas analisados. Dentre os fatores que podem explicar tal fato, ressalta-se a falta de informações aos agricultores sobre os programas, mas, sobretudo, o baixo valor passível de ser auferido por agricultor.

Palavras-chaves: Agricultura familiar, políticas públicas, Pronaf, Programa de Aquisição de Alimentos, Programa Nacional de Alimentação Escolar.

Abstract: With the understating of the Brazilian family farming as a social and productive category from the 90s, many public policy programs have been formulated to ensure its

1. Este trabalho faz parte do projeto de pós-doutorado da primeira autora, intitulado: "O impacto das políticas agrícolas nos municípios do Circuito das Frutas-SP", financiado pela Fapesp, sob a supervisão da segunda autora.

2. Profa. Dra. FCA/Unicamp, pesquisadora colaboradora na Feagri/Unicamp. E-mail: vanilde@yahoo.com

3. Profa. Titular Feagri/Unicamp, bolsista produtividade em pesquisa, CNPq e bolsista do Programa Nacional de Professor Visitante Sênior (PNPVS) da Capes, junto à UFSCar-Araras. E-mail: sonia@agr.unicamp.br 
propagation as a basic food producer, and to keep the man on the field. In this context, this paper intends to analyze the family farming in the municipalities of the "Fruit Circuit" in São Paulo State, Brazil, taking into account the importance of the access to the main public policy programs, which aim at strengthening this agriculture. Since this region is characterized by the strong presence of family farmers, we analyzed the following programs: Pronaf (National Program for Strengthening of Family Farming), PAA (Food Acquisition Program), and PNAE (National School Feeding Program), which have been the major initiatives of valuing this agriculture's sector in São Paulo. It was noticed that, considering the universe of the family farming in the studied municipalities, their participation in these public programs is still small. Among the factors that may explain this situation, we highlight the lack of information to farmers about the programs, but especially the low value paid to them.

Key-words: family farming, public polices, Pronaf, Food Aquisition Program, National School Feeding Program.

Classificação JEL: Q18.

\section{Introdução}

No Brasil, a agricultura familiar, segundo Lamarche (1993) foi profundamente marcada pelas origens coloniais da economia e da sociedade centradas em três pilares: a grande propriedade, a monocultura de exportação e o trabalho escravo. Apesar da importância da agricultura familiar brasileira ${ }^{4}$, historicamente, este setor foi sempre excluído das políticas públicas, uma vez que os recursos estatais eram direcionados para as grandes propriedades monocultoras de produtos destinados, sobretudo, à exportação. Neste sentido, os estímulos recebidos por parte do Estado asseguraram a modernização e a reprodução da grande propriedade monocultora, fazendo com que a agricultura familiar ocupasse um lugar subalterno na sociedade.

A partir dos anos 1990, a agricultura familiar no Brasil começou a ter reconhecimento enquanto categoria social e produtiva, através da formulação de políticas a seu favor. De forma geral, pode-se dizer que até então não havia nenhum tipo de política pública, com abrangência nacional, para os agricultores familiares.

A constatação e o reconhecimento da existência de um setor da agricultura, em que pre-

4. Ver Wanderley (1999); Lamarche (1993); Kageyama e Bergamasco (1990); Carneiro (1998); Schneider (1999); França, Del Grossi e Marques (2009); Kageyama, Bergamasco e Oliveira (2013). dominava o trabalho familiar, que genericamente associava família, trabalho e produção, passou a exigir ações por parte do Estado, em especial, a formulação de programas de políticas públicas. Em função disso, em 1994, foi criado o Provap (Programa de Valorização da Pequena Produção Rural), passo inicial para a constituição, dois anos depois, do primeiro e mais importante programa de política pública direcionado à agricultura familiar: o Pronaf.

A operacionalização deste programa exigiu uma definição legal da categoria Agricultor Familiar a fim de facilitar o seu acesso. A Lei $\mathrm{n}^{\mathrm{o}}$ 11.326/2006 traz em seu bojo esta definição determinando que se constitui agricultor familiar aquele que pratica atividades no meio rural, atendendo, simultaneamente, aos seguintes requisitos:

$$
\begin{aligned}
& \text { I - não detenha, a qualquer título, área maior } \\
& \text { do que } 4 \text { (quatro) módulos fiscais; } \\
& \text { II - utilize predominantemente mão de obra } \\
& \text { da própria família nas atividades econômicas } \\
& \text { do seu estabelecimento ou empreendimento; } \\
& \text { III - tenha renda familiar predominantemente } \\
& \text { originada de atividades econômicas vincula- } \\
& \text { das ao próprio estabelecimento ou empreen- } \\
& \text { dimento; } \\
& \text { IV - dirija seu estabelecimento ou empreendi- } \\
& \text { mento com a família. }
\end{aligned}
$$

Outro importante programa voltado para o fortalecimento da agricultura familiar brasileira 
é o PAA (Programa de Aquisição de Alimentos), que se dá por meio da utilização de compras governamentais como mecanismos de estímulo e de garantia de melhores preços para alimentos oriundos da agricultura familiar, criando um mercado institucional para tais produtos. Outro grande passo no sentido de promover a agricultura familiar no Brasil foi a Lei 11.947 de 16 de junho de 2009, em que se criou um elo institucional entre a alimentação escolar e a agricultura familiar local e/ou regional por meio de alterações no PNAE (Programa Nacional de Alimentação Escolar).

Desta forma, devido à importância que a agricultura brasileira possui, seja pela manutenção do homem no campo, seja pela produção de alimentos, torna-se importante compreender a dinâmica das políticas públicas no contexto da agricultura familiar, para que, assim, seja possível verificar os aspectos positivos e negativos referentes às mesmas. Neste sentido, este trabalho objetivou analisar os Programas: Pronaf, PAA e PNAE nos municípios que pertencem ao Circuito das Frutas, no estado de São Paulo, uma vez que essa região tem presença marcante de agricultores familiares.

Diversas pesquisas foram realizadas mensurando a importância da agricultura familiar no Brasil (KAGEYAMA e BERGAMASCO, 1990; VEIGA, 1995; FAO/INCRA, 1996; GUANZIROLLI e CARDIM, 2000); entretanto, somente a partir do Censo Agropecuário realizado em 2006 houve a inclusão deste segmento da agricultura na coleta dos dados censitários, permitindo verificar sua importância no cenário da agricultura nacional. Foram identificados 5.175.489 de estabelecimentos agropecuários no Brasil, ocupando área de 329,941 milhões de hectares. Destes, 4.367.902 eram estabelecimentos familiares, representando $84,4 \%$ dos estabelecimentos agropecuários, ocupando área de 80,25 milhões de hectares, o que corresponde a $24,3 \%$ da área total, com média de 18,37 hectares (BRASIL, 2009).

Além de ser importante fornecedora de alimentos, estudos comprovam a importância da agricultura familiar também enquanto principal fonte de ocupação da força de trabalho no meio rural brasileiro (GUANZIROLI et al., 2001; KAGEYAMA, BERGAMASCO e OLIVEIRA, 2013), e o Censo Agropecuário de 2006 registrou 12,3 milhões de pessoas vinculadas à agricultura familiar, o que representa $74,4 \%$ do pessoal ocupado, enquanto os estabelecimentos não familiares ocupavam 4,2 milhões de pessoas, correspondendo a $25,6 \%$ da mão de obra ocupada.

Dispondo de apenas $24,3 \%$ da área total dos estabelecimentos agropecuários, esta categoria da agricultura foi responsável por $38 \%$ do valor bruto da produção dos estabelecimentos em 2006. Guanziroli et al. (2001), analisando os dados do Censo Agropecuário de 1995/96, cujo VBP foi igual a 37,9\%, afirmam que a importância dessa contribuição fica ainda mais evidente se for considerado que parte dos estabelecimentos familiares é composta por lotes pequenos, ocupados pela moradia, e cultivos destinados ao autoconsumo.

O trabalho de Kageyama, Bergamasco e Oliveira (2013) realizado por meio de tabulações especiais do Censo Agropecuário de 2006 apresenta uma tipologia dos estabelecimentos agropecuários a partir da composição da mão de obra utilizada, resultando em quatro categorias: assentado, exclusivamente familiar, familiar com mão de obra contratada e não familiar. As autoras apresentam uma análise comparativa entre as categorias no que concerne a localização, número de estabelecimentos, área, pessoal ocupado, valor da produção e receitas e desigualdade da distribuição da terra dos estabelecimentos agropecuários, e afirmam que:

\section{Em todas as tipologias, o que se observa é o largo predomínio da agricultura familiar no Brasil, entre $70 \%$ e $90 \%$ dos estabelecimen- tos, abrigando mais da metade do pessoal ocupado na agropecuária (KAGEYAMA, BERGAMASCO e OLIVEIRA, 2013, p. 106).}

Diante do universo da agricultura familiar brasileira, bem como de sua importância social e econômica, apresenta-se, neste artigo, uma pesquisa sobre os programas de políticas públicas direcionadas para a agricultura familiar em 10 municípios localizados no Circuito das Frutas 
Paulista. Além desta introdução, este artigo está dividido em outras quatro seções. Na próxima seção, é apresentada a metodologia, contextualizando a área de estudo, bem como a forma de coleta dos dados. Na sequência, tem-se uma revisão bibliográfica sobre os três programas analisados, a qual norteou a discussão dos dados, apresentada na seção quatro. Finalizando, são tecidas algumas considerações sobre a discussão realizada.

\section{Metodologia}

\section{1. Área de Estudo}

A área escolhida para o estudo foi o Circuito das Frutas, compreendendo 10 municípios com presença marcante da agricultura familiar, pois, num total de 3.595 estabelecimentos agropecuários, 2.162 foram identificados como sendo de agricultura familiar, representando $60,14 \%$ do total de estabelecimentos (BRASIL. CENSO
AGROPECUÁRIO, 2006). Essa região tem se destacado principalmente na produção de frutas e no turismo rural, sendo um dos principais e melhores circuitos turísticos do estado de São Paulo. Os municípios que fazem parte do Circuito das Frutas são: Atibaia, Indaiatuba, Itatiba, Itupeva, Jarinu, Jundiaí, Louveira, Morungaba, Valinhos e Vinhedo, que têm em suas economias uma forte presença do setor rural, principalmente da fruticultura, com destaque para a produção de uva, morango, pêssego, goiaba, ameixa, caqui, acerola e figo.

A formação territorial dos municípios pertencentes ao Circuito das Frutas está ligada à chegada de imigrantes, europeus (a maioria italianos) e japoneses, para a região de Campinas, que foram responsáveis pela inserção de diversas culturas na região, através da introdução de seus costumes. A constituição do Circuito das Frutas é decorrente da cultura e tradições desses imigrantes, levando-se em consideração fatores que vão desde o cultivo das frutas até a formação de uma política de desenvolvimento do agroturismo (BERNARDI, 2009).

Figura 1. Mapa da localização do Circuito das Frutas (SP)

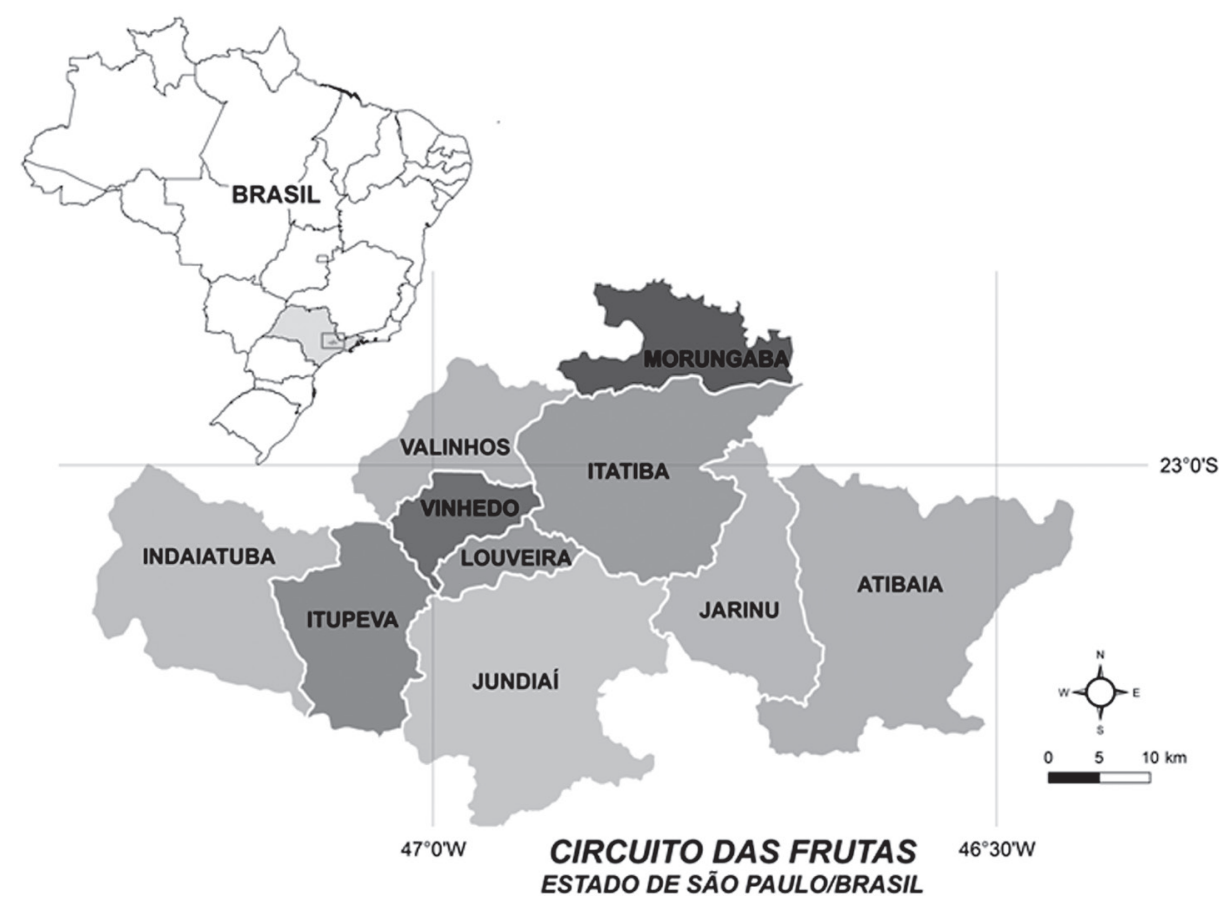

Fonte: Elaborado pelas autoras por meio de dados do IBGE. 
A origem do Circuito das Frutas remonta a meados dos anos 1990, quando produtores rurais da região buscavam no desenvolvimento do turismo rural alternativas para a viabilização econômica de suas propriedades. Mas apenas no ano 2000 um grupo composto por 27 produtores rurais reuniu-se para a constituição da Associação de Turismo Rural do Circuito das Frutas.

Com a organização da associação houve o apoio das prefeituras dos municípios participantes, e entidades como o Serviço Brasileiro de Apoio às Micro e Pequenas Empresas (Sebrae), de São Paulo, e o Serviço Nacional de Aprendizagem do Cooperativismo (Sescoop), de SP. Na mesma época, o interesse do governo estadual no desenvolvimento de roteiros turísticos propiciou a condição necessária para que, em 2 de outubro de 2002, fosse oficialmente instituído o Polo Turístico do Circuito das Frutas (PREFEITURA MUNICIPAL DE JUNDIAÍ, 2009).

O turismo rural só se destaca como atividade que permite o desenvolvimento econômico quando se localiza em áreas próximas às grandes cidades ou em locais especiais. Esta constatação permite vislumbrar um futuro promissor aos integrantes do Projeto "Circuito das Frutas", visto que estão inseridos bem próximos da região metropolitana de São Paulo, embora sejam locais que guardam a tradição de seus antepassados imigrantes italianos. Apesar de reconhecerem problemas resultantes da proliferação do turismo rural, autores como Labat e Perez (1994) reconhecem que, na Espanha, esta atividade econômica tem futuro como motor de desenvolvimento rural.

\subsection{Instrumentos para o levantamento dos dados}

Os dados sobre o PNAE foram levantados por meio de entrevistas com atores atuantes na concretização da Lei no 11.947/2009 nos municípios do Circuito das Frutas. Foram entrevistados, durante os períodos de janeiro a abril de 2012 e de março a julho de 2013, engenheiros agrônomos das Casas da Agricultura dos municí- pios, engenheiros agrônomos das Secretarias de Agricultura das prefeituras e nutricionistas das prefeituras municipais.

As informações sobre o PAA derivam de entrevistas, realizadas entre janeiro e abril 2012, com os engenheiros agrônomos das Casas da Agricultura dos municípios, e os engenheiros agrônomos das Secretarias de Agricultura das prefeituras.

Os dados referentes ao Pronaf foram adquiridos a partir da Base de Dados de Crédito, da Secretaria da Agricultura Familiar (SAF), do MDA (Ministério do Desenvolvimento Agrário), que foram posteriormente tabulados e analisados estatisticamente. Foi realizada uma análise estatística exploratória sobre os dados relativos ao volume de recursos do Pronaf liberados para os dez municípios paulistas, nas modalidades custeio e investimento, comparando com o total de recursos liberados para o Brasil e estado de São Paulo.

\section{Os programas de fortalecimento da agricultura familiar: uma revisão sobre o Pronaf, o PAA e o PNAE}

Ao se analisar as políticas públicas realizadas no Brasil, especialmente as políticas agrícolas voltadas à agricultura familiar, conclui-se que essa categoria começou a ser lembrada em 1994 a partir da criação do Provap (Programa de Valorização da Pequena Produção Rural). Apesar dos resultados bastante modestos em termos de fortalecimento e distribuição de crédito aos agricultores familiares, o Provap teve sua importância por permitir a diferenciação dos créditos por categorias de agricultores (MATTEI, 2005).

Até então, o agricultor familiar era considerado como miniprodutor para se enquadrar no Manual de Crédito Rural (MCR). Dessa forma, o agricultor familiar encontrava-se em duas situações que o prejudicavam, pois de um lado era obrigado a disputar crédito com os grandes produtores e, de outro, se via obrigado a seguir a mesma rotina das instituições financeiras para obter crédito que tinha um perfil voltado ao 
grande produtor rural (BELIK, 2000). O Provap sofreu reformulações em sua concepção, o que foi importante, pois essas modificações deram origem, em 1996, ao Pronaf.

O Pronaf foi fruto da organização e reivindicação dos trabalhadores rurais, que, no final da década de 1980, faziam diversas pressões sobre o Estado. Foi formulado baseado nos estudos realizados pela FAO/Incra (1994 e 2000), que definem conceitualmente a agricultura familiar e estabelecem um conjunto de diretrizes que deveriam orientar a formulação de políticas públicas apropriadas às particularidades dos distintos tipos de agricultores familiares (SCHNEIDER, MATTEI e CAZELLA, 2004).

Quando da sua criação, o Pronaf contava apenas com ações relacionadas ao crédito de custeio, sendo que a ampliação do programa para as linhas de investimentos, infraestrutura e serviços municipais, capacitação e pesquisa, ocorreu a partir de 1997, quando o programa passou a operar de forma integrada em todo território nacional.

Ao longo dos anos, o Pronaf passou por algumas mudanças institucionais e financeiras, que serviram para melhorar o acesso desse programa aos agricultores familiares. $\mathrm{O}$ volume de recursos vem aumentando progressivamente desde 1997, significando uma possibilidade concreta de acesso ao crédito a um número maior de agricultores familiares, considerando-se os diferentes graus de inserção nos mercados e as diferentes regiões do País. No Plano Safra de 2014/2015, o volume de recursos disponíveis para a agricultura familiar é de R \$24,1 bilhões.

Outro importante programa voltado para o fortalecimento da agricultura familiar brasileiro é o PAA (Programa de Aquisição de Alimentos), que estimula e fortalece a agricultura familiar por meio da utilização de compras governamentais como mecanismo de estímulo e de garantia de melhores preços para os alimentos oriundos da agricultura familiar, criando um mercado institucional para tais produtos.

O PAA insere-se no contexto de política pública voltada à agricultura familiar com ênfase na segurança alimentar e nutricional. Assim, o
PAA é o resultado da negociação de ideias e de interesses no fórum de comunidades de política pública, tornando-se o primeiro programa de política nacional para a agricultura familiar que se articula com a política de segurança alimentar e nutricional (GRISA, 2013). O mesmo foi instituído pelo artigo 19 da Lei no 10.696 de 02 de julho de 2003 e regulamentado pelo Decreto $\mathrm{n}^{\mathrm{o}}$ 6.447 de 07 de maio de 2008. É uma das ações do Projeto Fome Zero e surgiu de uma demanda da sociedade e de instituições públicas que trabalhavam para o fortalecimento da agricultura familiar.

O PAA foi implantado objetivando o incentivo à produção de alimentos pela agricultura familiar, o incentivo à comercialização desses produtos e a contribuição para que pessoas em situação de insegurança alimentar e nutricional pudessem ter acesso aos alimentos em quantidade, qualidade e regularidade. Ou seja, o PAA alia a política agrícola, enfocando a questão da comercialização, à segurança alimentar e nutricional da população. Tem também o objetivo de contribuir para a formação de estoques estratégicos e, com isso, permitir aos agricultores familiares armazenarem seus produtos para que esses possam ser comercializados a preços mais justos, além de promover a inclusão social no campo.

Deste modo, o PAA faz parte das políticas de Segurança Alimentar do Ministério do Desenvolvimento Agrário (MDA) e também do Plano Safra para a Agricultura Familiar. A fonte de recursos para o desenvolvimento do PAA é do Ministério do Desenvolvimento Social e Combate à Fome (MDS) e do MDA. Os executores do programa são a Companhia Nacional de Abastecimento (Conab), estados e municípios.

De acordo com Becker, Anjos e Caldas (2009), além dos objetivos explícitos do programa, existem outros que se encontram implícitos, como a distribuição de renda, a circulação de dinheiro na economia local, a exploração mais racional do espaço rural, o incentivo à agrobiodiversidade e a preservação da cultura alimentar regional. Com isso, o apoio à produção para o autoconsumo, a partir do excedente para comercialização e do subsídio ao consumo igualmente são benefícios 
indiretos que ocorrem em virtude da recuperação dos preços pagos aos produtores.

Em termos operacionais, o PAA possui seis modalidades: Compra Direta da Agricultura Familiar, Compra com Doação Simultânea, Apoio à Formação de Estoques pela Agricultura Familiar, Incentivo à Produção e ao Consumo de Leite-PAA Leite, Compra Institucional e, mais recentemente a modalidade Aquisição de Sementes. Desde a sua criação, em 2003, o PAA vem recebendo incremento no volume de recursos, embora ainda sejam muito inferiores às demandas da agricultura familiar.

Desde o início do programa, a modalidade que mais evoluiu foi a CPR Doação (Compra com Doação Simultânea), e o sucesso dessa modalidade pode estar ligado à possibilidade de comercialização de produtos característicos da agricultura familiar, como hortaliças, frutas, doces e biscoitos caseiros. Em relação à modalidade da Compra Direta, houve queda em 2010 e 2011, o que pode ser explicado pela baixa demanda para aquisição dos produtos, devido à alta nos preços. Porém, em 2012, esta modalidade obteve maior expressão em relação aos anos anteriores (BRASIL. CONAB, 2013).

Em 2012, a distribuição dos recursos do PAA foi maior na região Sul (39\%), seguidas pelas regiões Nordeste (26\%) e Sudeste (22\%) do Brasil e, com participações menores, as regiões Norte $(6 \%)$ e Centro-Oeste (7\%). Esses resultados demonstram que a demanda pelo PAA é variável, de acordo com as características próprias de cada região, em termos de organização social e acesso à informação (BRASIL. CONAB, 2013).

Durante os dez anos de operação do PAA pela Conab, milhares de famílias foram beneficiadas pela venda de seus produtos ao governo federal, obtendo garantia de renda e de melhoria na qualidade de vida. Em 2012, a região Sul foi a que apresentou o maior número de famílias de agricultores beneficiadas, seguida pela região Nordeste.

Ademais, neste mesmo ano, o maior segmento de agricultores familiares que acessou o PAA refere-se aos agricultores familiares tradicio- nais $(71 \%)$, seguido de agricultores assentados, cuja porcentagem foi de $23,8 \%$. Nesse sentido, sendo o PAA um programa que visa o atendimento de agricultores menos capitalizados, verifica-se que estes ainda possuem acesso restrito ao programa.

O PAA adquiriu mais de 3,5 milhões de toneladas de alimentos no período de 2003 a 2011 e passou a fornecer alimentos para quase 20 milhões de pessoas (BAVARESCO e MAURO, s/d). Apesar da pouca cobertura do PAA frente ao universo de agricultores familiares brasileiros, esse programa vem alcançando a cada ano seus objetivos, promovendo a geração de renda, sustentação de preços aos agricultores familiares e contribuindo para a segurança alimentar e nutricional da população urbana e rural. Desta forma, o PAA se consolida como um programa de política pública voltado para o agricultor familiar, garantindo, ao mesmo tempo, acesso a alimentos de qualidade para uma população em situação de insegurança alimentar.

Outro grande passo para a promoção da agricultura familiar está relacionado ao PNAE. O programa foi criado em 1954 pelo Ministério da Saúde e formalizado em 1955 pelo Ministério da Educação e Cultura (MEC), com o objetivo de reduzir a desnutrição escolar e, ao mesmo tempo, melhorar os hábitos alimentares dos alunos. Apesar de historicamente o PNAE apoiar a agricultura familiar, uma vez que adquire alimentos para a alimentação escolar, foi apenas com a Lei n. 11.947 de 16 de junho de 2009 que se criou um elo institucional entre a alimentação escolar e a agricultura familiar local ou regional. De acordo com o artigo 14 dessa lei, no mínimo 30\% dos recursos financeiros repassados pelo Fundo Nacional de Desenvolvimento da Educação (FNDE) aos estados e municípios para a compra de alimentos para o PNAE deverão ser utilizados para a aquisição de gêneros alimentícios oriundos da agricultura familiar e do empreendedor familiar rural ou de suas organizações.

O PNAE tem como órgão gestor o Ministério da Educação, com a coordenação e recursos do FNDE. Além de criar um novo mercado, o da alimentação escolar, essa iniciativa colabora para 
que a agricultura familiar se organize cada vez mais. Para quem adquire os alimentos, o resultado é mais qualidade na alimentação a ser servida, na manutenção e na apropriação de hábitos alimentares saudáveis e mais desenvolvimento local de forma sustentável (BRASIL, 2009).

A regulamentação da Lei no 11.947 ocorreu através da Resolução 38 do FNDE, que regula os repasses de recursos federais para a alimentação escolar, prevendo a aquisição direta de gêneros alimentícios da agricultura familiar por meio das Chamadas Públicas, tornando-se um instrumento mais objetivo para a implementação do artigo 14 da Lei $n^{-}$11.947, proporcionando um contato inicial de forma legal entre os agricultores familiares e as prefeituras (MALINA, 2012).

As chamadas públicas são meios de aquisição de produtos em substituição à necessidade em se realizar a licitação, ou seja, por meio das chamadas públicas ocorre a aquisição de produtos da agricultura familiar sem a necessidade de licitação. Porém, deve haver ampla divulgação da chamada e oferecer as informações necessárias às organizações da agricultura familiar que se interessem em fornecer para a alimentação escolar, como produto, período e local de entrega, quantidade, padrão de qualidade (MÜLLER, 2010).

Inicialmente, a Lei no $11.947 / 2009$ previa como o limite máximo de venda dos produtos da agricultura familiar o valor de $\mathrm{R} \$ 9.000,00$ por DAP, por ano. Em julho de 2012, esse limite máximo foi aumentado através da Resolução no 25 que alterou a redação dos artigos 21 e 24 da Resolução n. 38, de julho de 2009. Com a alteração, o limite passou para R\$20 mil por DAP/ano.

Assim, a aprovação da Lei n. 11.947/2009 foi mais um importante passo para o reconhecimento do papel econômico e social da agricultura familiar na produção de alimentos no Brasil, uma vez que essa categoria de agricultura representava, em 2006, 84,4\% do total de estabelecimentos rurais do Brasil, e foi responsável pela produção dos principais produtos destinados à alimentação humana (BRASIL. CENSO AGROPECUÁRIO, 2009).

\section{Análise dos programas de políticas públicas nos municípios do Circuito das Frutas (SP)}

\subsection{O Pronaf nos municípios do Circuito das Frutas (SP)}

A maior parte dos agricultores dos municípios que fazem parte do Circuito das Frutas é considerada familiar. A maioria das propriedades desses municípios tem área entre 2 e 50 ha, sendo que, nesse intervalo, a concentração das propriedades está entre 2 e 5 ha, com destaque para a produção de frutas, mas também de hortaliças (SÃO PAULO: SAA/CATI/IEA, 2008).

Desde a sua implantação, o Pronaf vem consolidando-se ano a ano como o principal programa de política pública para apoio à agricultura familiar no meio rural brasileiro. Entre 1996 e 2007, aumentaram sistematicamente tanto o número de beneficiários como o montante de recursos financeiros disponibilizados (AQUINO, 2009).

No Circuito das Frutas Paulista, quando se verifica o valor total contratado, percebe-se que o município de Louveira foi o que mais teve recursos do Pronaf (R\$ 8.794.110,46), seguido por Jarinu (R\$ 5.911.970,10), Jundiaí (R\$ 5.467.362,31) e Atibaia (R\$ 5.426.851,28). Na Tabela 1, é importante destacar o baixo número de contratos para o município de Valinhos, o que também se expressa em um baixo valor total contratado.

Na Tabela 1, ao apresentar os dados de cada município do Circuito das Frutas, verifica-se uma distribuição desigual entre eles, ou seja, há municípios como Vinhedo e Valinhos, cujos estabelecimentos familiares representavam $60,52 \%$ e $50,56 \%$, respectivamente (BRASIL, 2009); porém, nestes municípios, os agricultores pouco têm acessado os recursos do Pronaf, tanto a modalidade investimento quanto a de custeio. Em contrapartida, o município de Louveira, cujos estabelecimentos familiares representavam, em 2006, 60,40\% do total de estabelecimentos no município, foi o que mais teve agricultores que acessaram esse programa. Analisando as circuns- 
Tabela 1. Número total de contratos e volume total contratado (R\$) do Pronaf, de 2003/2004 a 2010/2011, nos municípios do Circuito das Frutas (SP)

\begin{tabular}{lcc}
\hline \multicolumn{1}{c}{ Município } & Número Total de Contratos & Valor Total Contratado (R\$) \\
\hline Atibaia & 392 & $5.426 .851,28$ \\
Indaiatuba & 328 & $4.853 .857,42$ \\
Itatiba & 205 & $4.127 .220,11$ \\
Itupeva & 169 & $3.378 .747,94$ \\
Jarinu & 288 & $5.911 .970,10$ \\
Jundiaí & 341 & $5.467 .362,31$ \\
Louveira & 505 & $8.794 .110,46$ \\
Morungaba & 151 & $2.384 .390,62$ \\
Valinhos & 134 & $2.009 .059,11$ \\
Vinhedo & 34 & $4.153 .31,46$ \\
Total Geral & 2547 & $\mathbf{4 2 . 7 6 8 . 9 0 0 , 8 0}$ \\
\hline
\end{tabular}

Fonte: SAF/MDA, 2011.

tâncias atuais em Valinhos e Vinhedo, tem-se percebido que áreas anteriormente denominadas de rurais, têm, atualmente, dado lugar à construção de condomínios de luxo, havendo uma crescente urbanização e perda de área rural para a formação desses condomínios.

A seguir, é apresentada a análise descritiva dos percentuais de valor financiado e contratos correspondentes ao total de valor financiado/ número de contratos para os dez municípios do Circuito das Frutas sobre o total de valor financiado/número de contratos no estado de São Paulo por período (ano agrícola) e modalidade.

Verifica-se, na Tabela 2, que os agricultores familiares dos municípios do Circuito das Frutas (SP) pouco contratam o Pronaf, pois a porcentagem de valor financiado e do número de contratos nessa região é pequena dentro do estado de São Paulo, visto que, dos 150.900 estabelecimentos familiares, que correspondem a $66,29 \%$ do total, identificados neste estado, 2.162 estabelecimentos familiares estão situados no Circuito das Frutas. Porém, a agricultura familiar dos municípios deste Circuito representa mais de 60\% dos estabelecimentos rurais, dado que confirma a forte presença deste tipo de agricultura nos municípios pesquisados. Deve-se salientar que a agricultura paulista possui forte vinculação com o agronegócio, com destaque para a produção de café, cana-de-açúcar e laranja. Assim, no estado de São Paulo, como em outros estados, verifica-se que o crédito do Pronaf direciona-se para o custeio de culturas voltadas à exportação, ou commodities agrícolas, culturas pouco produzidas na região do Circuito das Frutas. Tal fato pode ser confirmado através dos dados apresentados no trabalho realizado por Grisa, Wesz Junior e Buchweitz (2014), que, ao analisarem o desempenho do Pronaf no Brasil, verificaram que o crédito para o custeio agrícola financiou, no período de 1999 a 2012, majoritariamente produtos como milho, soja, café e fumo, sendo que o milho e a soja ocuparam as duas primeiras posições.

Além disso, de acordo com os engenheiros agrônomos das Casas de Agricultura dos municípios, os agricultores do Circuito das Frutas, até mesmo pela história de formação da região, não têm o "costume" de adquirir financiamento, muitas vezes por desconfiança e/ou medo em contrair uma dívida, preferindo, assim, investir na propriedade com recursos próprios ou mesmo não realizar investimentos. 
Tabela 2. Percentuais de valor financiado e número de contratos no estado de São Paulo em relação aos municípios do Circuito das Frutas

\begin{tabular}{cccc}
\hline Ano Agrícola & Modalidade & \% Valor financiado & \% Número de contratos \\
\hline \multirow{2}{*}{$2003 / 2004$} & Custeio & 1.5247 & 0.98953 \\
& Investimento & 0.29675 & 0.29350 \\
\hline \multirow{2}{*}{$2004 / 2005$} & Custeio & 1.57108 & 1.00591 \\
& Investimento & 0.18451 & 0.12070 \\
\hline \multirow{2}{*}{$2005 / 2006$} & Custeio & 1.16556 & 0.88253 \\
& Investimento & 0.59566 & 0.48214 \\
\hline \multirow{2}{*}{$2006 / 2007$} & Custeio & 1.54467 & 1.21290 \\
& Investimento & 0.51762 & 0.35006 \\
\hline \multirow{2}{*}{$2007 / 2008$} & Custeio & 1.33744 & 0.96204 \\
& Investimento & 0.77256 & 0.63830 \\
\hline \multirow{2}{*}{$2008 / 2009$} & Custeio & 1.49456 & 1.18357 \\
& Investimento & 3.12821 & 1.79680 \\
\hline \multirow{2}{*}{$2009 / 2010$} & Custeio & 1.35853 & 1.13965 \\
& Investimento & 2.07865 & 1.33934 \\
\hline \multirow{2}{*}{$2010 / 2011$} & Custeio & 1.30674 & 1.10198 \\
& Investimento & 1.77664 & 1.20236 \\
\hline \multirow{2}{*}{$2011 / 2012$} & Custeio & 1.17071 & 1.05404 \\
& Investimento & 1.11306 & 0.93825 \\
\hline
\end{tabular}

Fonte: Dados da Pesquisa, 2012.

\subsection{O PAA nos municípios do Circuito das Frutas}

A análise do PAA enquanto ação demonstra um novo sentido das políticas públicas para a agricultura familiar, uma vez que esse programa é mais próximo da sociedade civil, mais baseado na organização dos agricultores, tendo uma estrutura cujo trabalho está relacionado com uma produção mais diversificada.

Em 2012, o PAA atendeu cerca de 20 mil entidades socioassistenciais e mais de 190 mil agricultores familiares em todo o Brasil. Nos 10 anos da existência do programa, mais de $\mathrm{R} \$ 5$ bilhões foram investidos para a obtenção de produtos da agricultura familiar, e a previsão para 2014 é que 250 mil agricultores sejam beneficiados (BRASIL. MDA, 2013).

No estado de São Paulo, de acordo com dados da Conab, participaram do programa, em 2012, um total de 18.523 agricultores distribuídos nas diversas categorias, sendo que a maior participação no estado foi dos assentados $(51,90 \%)$, seguidos pelos agricultores familiares tradicionais $(46,10 \%)$. O inverso ocorreu no Brasil, uma vez que a grande maioria de agricultores que participaram do PAA (em 2012) foi de agricultores familiares, representando $71 \%$. No âmbito nacional, há destaque para o aumento na participação de assentados e agroextrativistas, que praticamente dobraram a sua participação, se comparados a 2011.

Constatou-se que, em 2012, seis agricultores familiares de Atibaia realizaram convênio para entregarem produtos ao PAA. Na região estudada, apenas o município de Atibaia possuía agricultores que forneciam gêneros alimentícios ao PAA. Notou-se que os agricultores familiares dos municípios do Circuito das Frutas têm pouco interesse em participar de organizações como associações, mas sobretudo de cooperativas. Com exceção dos agricultores do município de Atibaia, que já vinham desenvolvendo um trabalho com a Cooperativa "Entre Serras e Águas", localizada em Bragança Paulista, nenhum outro município tem uma cooperativa de agricultores familiares com o mesmo interesse. Existe a presença de cooperativas nos demais municípios, a exemplo da Cooperativa Agrícola Nossa Senhora das Vitórias, formada por vitivinicultores do município de 
Jundiaí, porém, não é considerada familiar por não ter em seu quadro no mínimo $60 \%$ dos cooperados com DAP.

Eles são agricultores (cooperados), pequenas propriedades, trabalham em família, mas tem uma renda superior do que é determinado pela DAP ou tem mais funcionários do que permite; então é o pai, o filho, a esposa e mais três funcionários, porque a fruticultura exige, então ele não tem DAP, ele é agricultor familiar, mas não consegue tirar a DAP. [...] Esses agricultores não têm a DAP e participam da cooperativa, e isso faz com que a cooperativa não consiga a DAP jurídica (Entrevista Sr. S.M.P., engenheiro agrônomo da prefeitura de Jundiaí, 2012).

$\mathrm{O}$ fato de as propriedades terem pequenas áreas faz com que a maior parte delas seja conduzida única e exclusivamente pela família, ou seja, são propriedades cuja base é familiar. "Estudos indicam que na região, as propriedades agrícolas produtoras de frutas são em sua maioria conduzidas pelo trabalho predominante da própria família" (OTANI et al., 2012, p. 56).

Em entrevista realizada com um dos agentes públicos municipais de Jarinu, foi possível constatar que ainda há muito que ser trabalhado no quesito organização dos agricultores.

Talvez falte um pouco para o produtor mais organização, porque apesar de nós termos duas associações no município, a participação é pequena, então se o produtor procurasse mais as associações eu acho que esse trâmite seria muito mais fácil. Porque nós vemos até em outros estados que têm funcionado muito bem, é uma alavanca de renda, de geração de emprego e renda (Entrevista, Sr. J.B.S., engenheiro agrônomo Casa da Agricultura de Jarinu, 2012).

Falta ainda, nesses municípios, mais organização por parte dos agricultores para participarem das políticas vigentes para a agricultura familiar. Contudo, constatou-se que, além da questão de organização, há uma carência entre os agricultores por serviços de assistência técnica e extensão rural públicos nessa região, sendo este um dos fatores que contribuíram para a não participação no PAA, uma vez que os mesmos desconheciam esse programa.

Para que uma política pública atinja o seu potencial, tão importante quanto a estrutura e o funcionamento da rede de agentes participantes, torna-se fundamental sua apropriação pelos diferentes agentes. Os agricultores devem se apropriar do programa, entender os seus objetivos, seus limites e sua estrutura operacional, pois somente assim será possível a constituição de redes locais com elevada coesão social, onde os diferentes agentes se ajudam mutuamente (BERGAMASCO, BORSATTO e ESQUERDO, 2013, p. 45).

Nos municípios do Circuito das Frutas, muitos agentes públicos ligados aos serviços de assistência técnica e extensão rural desconheciam o PAA. Além disso, outros motivos também contribuíam para que os agricultores dessa região não participassem do PAA, entre eles, podem ser citados o baixo valor do programa (à época da pesquisa) e a existência de um canal de comercialização já estabelecido por eles, a Ceasa (Centrais Estaduais de Abastecimento), em Campinas, e a Ceagesp (Companhia de Entrepostos e Armazéns Gerais do Estado de São Paulo).

Apenas no município de Atibaia foram identificados agricultores que participavam do PAA. Inicialmente, esses agricultores entregavam seus produtos para a prefeitura de Santo André, que, através da Craisa (Companhia Regional de Abastecimento Integrado de Santo André), adquiria os alimentos e os encaminhavam ao Banco de Alimentos do município.

Alguns produtores já entregavam para Santo André, um caminhão de 12 toneladas sai de Santo André e vai até Socorro pegando os produtos, o que tiver eles pegam, o importante é fechar a cota de $\mathrm{R} \$ 4.500,00$. Seis produtores estão entrando no PAA de Santo André, não deu tempo de colocar aqui em Atibaia.

Santo André compra esses alimentos porque possui bastante entidade cadastrada na prefei- 
tura e o Banco de Alimentos tem condições de pegar mais produto por produtor (Entrevista Sr. C.G.A, engenheiro agrônomo, Prefeitura de Atibaia, 2012).

A modalidade do PAA que esses seis agricultores familiares de Atibaia estavam entregando para a Craisa de Santo André era a Compra Antecipada da Agricultura Familiar, cujo valor máximo correspondia, na época, a $\mathrm{R} \$ 4.500,00$ por DAP por ano.

A partir de 2012, o município de Atibaia, através da prefeitura, também começou a adquirir produtos dos agricultores familiares com o PAA. Em Atibaia, a modalidade do PAA é a Doação Simultânea, para que os alimentos sejam encaminhados às entidades socioassistenciais credenciadas na prefeitura. Dessa forma, com o PAA, o poder público municipal tem mais uma oportunidade para estimular a agricultura familiar, conseguindo um mercado consumidor para os seus produtos a preços melhores do que os praticados no mercado.

Apesar de serem apenas seis agricultores que participam do programa em Atibaia, de acordo com os agentes públicos municipais, o PAA está sendo importante para eles, pois estão conseguindo eliminar a figura do "atravessador", que acabava ficando com grande parte dos lucros. Com o PAA, o agricultor tem a possibilidade de aumentar a sua renda, contribuindo, dessa forma, para a sua manutenção e permanência no campo.
O PAA significa novas possibilidades de ingressar no mercado e, ao mesmo tempo sobretudo para as famílias do Sul e Centro-Oeste do Brasil -, oportunidades para distanciar- se dos mercados de commodities agrícolas que se mostram inadequados às especificidades dessa categoria social, principalmente no que se refere à escala de produção e ao padrão tecnológico. Ademais, a garantia de comercialização significa o fortalecimento da autonomia dos agricultores em relação aos atravessadores (GRISA et al., 2011).

Ao todo, em 2012, o município de Atibaia adquiriu, por meio do convênio com o PAA, $30.148 \mathrm{~kg}$ de alimentos, que foram distribuídos às creches municipais. Os agricultores entregavam os produtos semanalmente em um ponto de recebimento da prefeitura que se encarrega de entregar para 15 creches beneficiadas no município. Os agricultores receberam os recursos nos prazos estipulados no convênio, não havendo atraso nos pagamentos.

\begin{abstract}
Além de fornecermos diretamente, sem intermediários, também não temos despesas com logística e acondicionamento dos produtos, o que aumenta o nosso lucro. Fora esta venda para o PAA, só vendemos no Ceasa. A diferença é que, no programa, vendemos de forma direta, para os próprios compradores. No Ceasa não, acabo tendo essas despesas com transporte e caixa, e a venda é consignada.

O caqui mesmo, cuja minha produção é maior, eu preferia vender sempre para o PAA do que no varejo (Sr. G. A. M., agricultor familiar, 2012).
\end{abstract}

Tabela 3. Lista de produtos fornecidos pelo agricultor ao PAA, em Atibaia, 2012

\begin{tabular}{|c|c|c|c|}
\hline Agricultores & Produtos entregues & Quantidade (kg) & Valor (R\$) \\
\hline A.H.F & Goiaba & 1.875 & $4.500,00$ \\
\hline A.K.A. & $\begin{array}{l}\text { Chuchu } \\
\text { Rúcula }\end{array}$ & $\begin{array}{l}460 \\
180 \\
\end{array}$ & $\begin{array}{l}253,00 \\
594,00 \\
\end{array}$ \\
\hline A.L.T. & Chuchu & 8.182 & $4.500,00$ \\
\hline E.S.S. & Chuchu & 8.180 & $4.499,00$ \\
\hline G.A.M. & $\begin{array}{c}\text { Chuchu } \\
\text { Caqui }\end{array}$ & $\begin{array}{l}1.090 \\
2.000 \\
\end{array}$ & $\begin{array}{c}599,50 \\
3.900,50 \\
\end{array}$ \\
\hline M.A.T. & Chuchu & 8.181 & $4.499,55$ \\
\hline Total & & 30.148 & $23.345,55$ \\
\hline
\end{tabular}

Fonte: Dados da pesquisa. MDS/SAGI, 2013. 
Embora seja um importante programa que tem contribuído para a melhoria de renda dos agricultores familiares e para a diversificação da sua produção, dos 645 municípios existentes no estado de São Paulo, o PAA está presente em apenas $20 \%$ deles, o que corresponde a 131 municípios paulistas. Assim, nota-se que deve haver um intenso trabalho de incentivo à participação dos agricultores familiares no programa.

Muitos problemas estão sendo identificados no País em relação ao PAA, o que pode acarretar na pequena participação de agricultores. Dentre os problemas observados, destacam-se atrasos no pagamento, questões de logística e exigência de documentação para acessar o programa (DAP).

Em Atibaia, a prefeitura pretende ampliar o número de agricultores participantes do programa, bem como os produtos e a quantidade. No final de 2012, oito agricultores aguardavam a chamada da prefeitura para poderem participar do PAA. Esses agricultores entregariam produtos como poncã, morango e hortaliças, diversificando, desta maneira, os alimentos às entidades beneficiárias e promovendo a inclusão de mais agricultores no programa.

Dentre os pontos positivos do PAA no município de Atibaia, podem ser destacados a melhoria de renda dos agricultores, a venda direta eliminando a presença do atravessador, o que consequentemente acarreta na comercialização de produtos a preços mais elevados, a contribuição para a manutenção e permanência do agricultor no meio rural e, sobretudo, o reconhecimento da agricultura familiar local.

Deve-se ressaltar que a participação do poder público municipal é fundamental para a implementação e o êxito do programa, estimulando, dessa forma, mais um canal de comercialização da agricultura familiar local. Esse é o principal obstáculo a ser superado nos municípios do Circuito das Frutas.

\subsection{A implementação da Lei $n^{\circ} 11.947 / 2009$, do PNAE, nos municípios do Circuito das Frutas (SP)}

A reformulação do PNAE e a inserção da agricultura familiar local e/ou regional como fornecedora de alimentos para a alimentação escolar contribuiu para a promoção de uma alimentação mais saudável e para o respeito dos hábitos alimentares baseados no consumo de produtos locais.

De acordo com Triches (2010), com a Lei no $11.947 / 2009$, o PNAE passou a ter grande potencial para ser utilizado como uma política estruturante, uma vez que, ao adquirir os produtos de agricultores locais, se constituiria num novo nicho de mercado para a agricultura familiar. Isso contribui para a promoção de empregos e trabalho no meio rural, diminuição do êxodo e, consequentemente, da pobreza rural e urbana.

A inserção da agricultura familiar no PNAE teve que ser compreendida pelas prefeituras municipais que passaram a reservar no mínimo $30 \%$ dos recursos repassados pelo FNDE para a compra de alimentos da agricultura familiar para a merenda escolar. Os municípios do Circuito das Frutas contam com uma rede de ensino que abrange escolas urbanas e rurais, incluindo creches, pré-escola, escolas de ensino fundamental e médio, escolas para a educação de jovens e adultos (EJA) e escolas de atendimento educacional especializado (AEE) (educação inclusiva). Dessa forma, diariamente são muitas as refeições que devem ser preparadas para a merenda escolar, abrindo, assim, um novo e importante mercado para os agricultores familiares locais comercializarem seus produtos. Nesse sentido, o PNAE pode ser considerado como o maior programa de suplementação alimentar da América Latina, considerando-se o tempo de atuação, sua continuidade, o compromisso constitucional desde 1988, o caráter universal, o número de alunos 
Tabela 4. Valores (R\$) recebidos pelos municípios para serem destinados à compra de produtos da agricultura familiar para a alimentação escolar, conforme a Lei n. 11.947/2009 (Merenda Escolar - 30\%)

\begin{tabular}{lccc}
\hline \multirow{2}{*}{ Municípios } & \multicolumn{1}{c}{ Anos } & 2012 \\
\cline { 2 - 4 } & 2010 & 2011 & $586.562,40$ \\
Atibaia & $500.562,00$ & $550.314,00$ & $906.357,60$ \\
Indaiatuba & $751.150,80$ & $788.940,00$ & $458.928,00$ \\
Itatiba & $417.672,00$ & $394.848,00$ & $217.285,20$ \\
Itupeva & $190.386,00$ & $196.974,00$ & $129.942,00$ \\
Jarinu & $113.292,00$ & $119.682,00$ & $1.324 .764,00$ \\
Jundiaí & $1.204 .092,00$ & $1.349 .334,00$ & $196.606,80$ \\
Louveira & $170.136,00$ & $169.524,00$ & $55.054,80$ \\
Morungaba & $52.326,00$ & $53.226,00$ & $344.296,80$ \\
Valinhos & $316.080,00$ & $323.730,00$ & $271.907,28$ \\
Vinhedo & $225.345,24$ & $236.682,00$ & $\mathbf{4 . 4 9 1 . 7 0 4 , 8 8}$ \\
Total & $\mathbf{3 . 9 4 1 . 0 4 2 , 0 4}$ & $\mathbf{4 . 1 8 3 . 2 5 4 , 0 0}$ & \\
\hline
\end{tabular}

Fonte: FNDE, 2013. Dados da pesquisa, 2012/2013.

atendidos e o volume de investimentos já realizados (TURPIN, 2009).

Os recursos destinados aos municípios do Circuito das Frutas para a aquisição de produtos alimentícios da agricultura familiar para a merenda escolar têm aumentado gradativamente. As cidades que mais receberam recursos para a alimentação escolar, cujos valores são superiores a $\mathrm{R} \$ 700.000,00$, foram Jundiaí e Indaiatuba, pois são grandes municípios e contam com maior número de alunos matriculados nas escolas.

Apesar do grande volume de recursos repassados pelo FNDE aos municípios para que esses adquiram produtos da agricultura familiar para a merenda escolar, verificou-se que a maioria ainda não aplicou todo o montante dos recursos (Tabela 5).

Apesar de o Circuito das Frutas englobar 10 municípios com presença marcante da agricultura familiar, principalmente para a produção de frutas e para o turismo rural, verificou-se que o processo de inserção de agricultores familiares ao PNAE ainda é bastante lento.

Em 2010, apesar de quatro municípios (Indaiatuba, Itupeva, Itatiba e Louveira) terem lançado chamada pública para a compra de produtos dos agricultores familiares, verificou-se que apenas o município de Louveira utilizou parte desse recurso. Ainda assim, o valor utilizado foi bastante baixo, apenas $\mathrm{R} \$ 4.025,00$, que foram

Tabela 5. Valores (R\$) gastos pelos municípios para a compra de produtos da agricultura familiar para a alimentação escolar, conforme Lei n. 11.947/2009

\begin{tabular}{lccc}
\hline \multirow{2}{*}{ Municípios } & \multicolumn{2}{c}{ Anos } & 2012 \\
\cline { 2 - 4 } & 2010 & 2011 & $391.041,00$ \\
Atibaia & 0,00 & $186.438,00$ & 0,00 \\
Indaiatuba & 0,00 & 0,00 & $72.230,40$ \\
Itatiba & 0,00 & $418.086,00$ & 0,00 \\
Itupeva & 0,00 & 0,00 & $79.997,27$ \\
Jarinu & 0,00 & $14.351,00$ & $\mathrm{NI}^{*}$ \\
Jundiaí & 0,00 & $\mathrm{NI}^{*}$ & 0,00 \\
Louveira & $4.025,00$ & 0,00 & $9.069,25$ \\
Morungaba & 0,00 & $20.000,57$ & 0,00 \\
Valinhos & 0,00 & 0,00 & $80.500,00$ \\
Vinhedo & 0,00 & $6.700,00$ & \\
\hline
\end{tabular}

* Dados não informados pela prefeitura.

Fonte: Dados da pesquisa, 2012/2013. 
destinados à compra de alface, rúcula e pimentão de três agricultores familiares do município. Quando o município não utiliza o recurso, este pode ser repassado para o ano seguinte; assim, além dos $30 \%$, as prefeituras contam ainda com o saldo do ano anterior.

A Lei no 11.947 foi implementada em 2009; dessa forma, nesse ano não houve o lançamento de nenhuma chamada pública pelos municípios, pois os mesmos ainda estavam se adequando frente à nova realidade de aquisição de produtos para a merenda escolar. Assim, diversos agentes municipais disseram que a chamada pública realizada em 2010 foi uma forma de aprendizado, servindo como um piloto sobre essa nova modalidade de compra. O atraso no cumprimento da lei pode ser justificado pelo artigo 14, parágrafo 2 , da Lei no 11.947/2009, que desobriga de responsabilidade a administração municipal por não cumprir os 30\% de compras da agricultura familiar em três situações: i) quando os produtores não tiverem a documentação adequada; ii) quando não puderem manter a constância no fornecimento e iii) quando as condições higiênico-sanitárias forem inadequadas.

Em 2011, oito municípios lançaram chamadas públicas, porém, apenas cinco deles (Atibaia, Itatiba, Jarinu, Morungaba e Vinhedo) destinaram parte do recurso do FNDE para a compra de gêneros alimentícios da agricultura familiar. O município de Itatiba foi o que mais utilizou os recursos, gastando $\mathrm{R} \$ 418.086,00$, valor superior ao que foi repassado pelo FNDE. Isso se explica pelo fato de que havia um saldo do ano de 2010, sendo parte deste saldo utilizado em 2011, mais o valor do recurso de 2011. O recurso utilizado em 2011 foi para a compra de suco integral de uma cooperativa de agricultores familiares do Rio Grande do Sul, não havendo a participação de agricultores familiares locais.

Em 2010 não foi comprado nada da agricultura familiar, não veio ninguém, fez a chamada e não apareceu ninguém. Aí ficou depositado no banco, ficou guardado lá, em 2011 nós abrimos novamente, conseguimos gastar um montante de 400 mil, abrimos uma em janeiro, com suco de laranja, leite, vários produtos, o único que deu certo foi o suco de laranja, era suco de laranja integral, em embalagem individual. Os 400 mil de 2010 foram repassados para essa compra em 2011. O valor de 2011 está acumulado esse ano ainda (2012). Sobraram uns 20-30 mil de 2010 (Entrevista Sra. K.H., nutricionista da prefeitura de Itatiba, 2012).

Em 2011, Morungaba foi o município que mais gastou (proporcionalmente) os recursos, utilizando $37,6 \%$ do total, para a compra de hortifrutigranjeiros como acelga, chicória, chuchu, brócolis, alface, couve manteiga, cheiro verde e manga orgânica. Outro município que conseguiu comprar produtos da agricultura familiar em 2011 foi Atibaia, utilizando quase $34 \%$ dos recursos.

Em 2012, os municípios que gastaram parte do recurso repassado pelo FNDE para a compra de produtos da agricultura familiar para a merenda escolar foram os mesmos de 2011, com a diferença de que conseguiram utilizar maior volume de recursos em 2012, comparado ao que foi utilizado em 2011. Atibaia utilizou 67\% dos recursos para a compra de produtos da agricultura familiar, como alface, cenoura, brócolis, banana e outras frutas, verduras e legumes.

A implementação da Lei no $11.947 / 2009$ no município de Atibaia foi muito importante, pois possibilitou a inovação do cardápio da merenda escolar ao adquirir gêneros alimentícios orgânicos da agricultura familiar local. Em 2013, de 30\% a $40 \%$ dos produtos adquiridos dos agricultores familiares para a merenda escolar em Atibaia eram orgânicos.

Produtos orgânicos que serão entregues, coloca aí, folhosas, raízes e tubérculos, entra tudo, frutas. As frutas vão entrar poncã, caqui, banana, uva e morango. Mandioca também, inclusive quase toda mandioca vai ser orgânica, o inhame, quase todo o inhame está sendo orgânico. Hoje, de produtos orgânicos vamos colocar aí, de 30\% a 40\% (Entrevista C.G.A, ex-presidente da cooperativa "Entre Serras e Águas" e eng. agrônomo da prefeitura de Atibaia, 2012). 
O contrato em Atibaia envolve 51 produtores da cooperativa Entre Serras e Águas (15 do município de Atibaia) para fornecer 31 itens, dos quais 10 são orgânicos (ESQUERDO e BERGAMASCO, 2012).

O município de Jarinu, em 2012, utilizou $62 \%$ dos recursos repassados pelo FNDE para a compra de alimentos da agricultura familiar, que foram utilizados para comprar hortifrutigranjeiros, entre eles, cenoura, chuchu, beterraba, abobrinha, couve-flor, couve-manteiga, alface, mandioca, banana.

O município de Valinhos foi o único a não realizar nenhuma chamada pública até 2012, indicando não haver interesse do setor público municipal na ligação entre agricultura familiar e alimentação escolar.

Nota-se que há grandes dificuldades ainda a serem superadas, mas, por outro lado, há que se considerar o avanço desse programa no reconhecimento da importância da agricultura familiar local como fornecedora de alimentos, na maioria das vezes, de melhor qualidade, contribuindo para a segurança alimentar e nutricional das crianças.

\section{Considerações finais}

Com exceção de seis agricultores do município de Atibaia, verificou-se que a maioria dos agricultores familiares dos municípios do Circuito das Frutas não tem acesso ao PAA, principalmente por dois motivos: falta de informação, ou seja, há um desconhecimento dos produtores e até mesmo dos gestores públicos municipais sobre o programa; e o baixo valor sobre o limite de comercialização por agricultor/ano, o que não os estimula a acessá-lo. Entretanto, deve-se salientar que uma das funções do PAA é se apresentar como mais uma opção de comercialização dos produtos da agricultura familiar. $\mathrm{O}$ aumento do valor do programa poderia acarretar na concentração de agricultores fornecedores de alimentos no município.

Ao ser verificado o número de contratos e o volume de crédito do Pronaf nos municípios do
Circuito das Frutas, percebeu-se que, após 17 anos do início dessa política, ainda são poucos os agricultores que o acessam. Percebeu-se que tanto o valor financiado quanto a quantidade de contratos nos municípios é pequena frente ao volume de recursos financiados pelo programa no estado de São Paulo.

Para o PNAE, verificou-se que os municípios, exceto Valinhos, estão tentando cumprir a lei ao realizarem as Chamadas Públicas. Porém, a simples publicação da Chamada Pública não é garantia de que, no mínimo, os $30 \%$ dos recursos repassados pelo FNDE aos municípios sejam gastos com aquisição de gêneros alimentícios da agricultura familiar, uma vez que, com exceção de Atibaia, nenhum município conseguiu gastar esse valor com a agricultura familiar local, regional ou de outros estados do País.

Nesse sentido, foram identificados alguns problemas para que o programa realmente cumpra com o seu objetivo, como falta de documentação por parte dos agricultores (principalmente a DAP), o baixo valor do programa (na época de realização da pesquisa), a falta de organização dos produtores, a descentralização dos pontos de entrega dos produtos nos municípios, aumentando o custo do agricultor.

Ainda que todos esses problemas sejam resolvidos, se não houver vontade política para a promoção e o fortalecimento da agricultura familiar local e regional, o programa dificilmente terá êxito nos municípios.

\section{Referências bibliográficas}

AQUINO, J. R. de. Avanços e limites da política de crédito do PRONAF no Brasil (1996-2008): uma reflexão crítica. In: XLVII Congresso da Sociedade Brasileira de Economia, Administração e Sociologia Rural. 2009. Porto Alegre-RS, Anais..., Porto Alegre: SOBER, 2009. CD-ROM.

BACCARIN, J. G., BUENO, G., ALEIXO, S. E. e SILVA, D. B. P. da. Agricultura familiar e alimentação escolar sob vigência da Lei 11.947/2009: adequação das chamadas públicas e disponibilidade de produtos no estado de São Paulo em 2011.In: 50ํㅡ Congresso da Sociedade 
Brasileira de Economia, Administração e Sociologia Rural. 2012. Vitória-ES, Anais..., Vitória: SOBER, 2012. CD-ROM.

BAVARESCO, P. e F. MAURO (2013). Agricultura familiar brasileira no Programa Nacional de Alimentação Escolar: garantia de mercado aos agricultores e de segurança alimentar e nutricional aos alunos da rede pública de ensino. Mimeo, Disponível em: <http://www.rlc.fao.org/fi 106 leadmin/templates/fondobrasil/documentos/Foro_ expertos/Articulos/Artigo_Pedro_Bavaresco.pdf > Acesso em: 20 set. 2013.

BECKER, C., ANJOS, F. S. dos e CALDAS, N. V. Políticas públicas estruturantes e segurança alimentar: o caso do PAA. In: 47ํㅡㄹ Congresso da Sociedade Brasileira de Economia, Administração e Sociologia Rural. 2009. Porto Alegre. Anais..., Porto Alegre: SOBER, 2009. CD-ROM.

BELIK, W. PRONAF: Avaliação da operacionalização do programa. In: CAMPANHOLA, C. e GRAZIANO da SILVA, J. (Orgs.). O Novo Rural Brasileiro - Políticas Públicas. Jaguariúna: Embrapa, volume 4, p. 93-116, 2000.

BERGAMASCO, S. M. P. P., BORSATTO, R. S. e ESQUERDO, V. F. S. Políticas públicas para a agricultura familiar no Brasil: reflexões a partir de estudos de casos no estado de São Paulo. Revista Interdisciplinaria de Estudios Agrarios, Buenos Aires-Argentina, n. 38, p. 25-50, 2013.

BERNARDI, A. Estratégias de Desenvolvimento Local E Regional: um estudo sobre o Circuito das Frutas e sua articulação com a Região Metropolitana de Campinas (SP). 2009. 182 f. Dissertação (Mestrado em Geografia) - Instituto de Geociências, Universidade Estadual de Campinas, 2009.

BRASIL. Lei $n^{0}$ 11.947, de 16/06/2009: Dispõe sobre o atendimento da alimentação escolar e do Programa Dinheiro Direto na Escola aos alunos da educação básica; altera as Leis nos 10.880, de 9 de junho de 2004, 11.273, de 6 de fevereiro de 2006, 11.507, de 20 de julho de 2007; revoga dispositivos da Medida Provisória no 2.178-36, de 24 de agosto de 2001, e a Lei no 8.913, de 12 de julho de 1994; e dá outras providências. Brasília-DF. Disponível em: <http://www.mda.gov.br/portal/saf/ programas/alimentacaoescolar/2478043>. Acesso em: 15 maio 2010.

. MDA/IBGE. Censo Agropecuário 2006 Agricultura Familiar, Primeiros Resultados. Rio de Janeiro: IBGE. 2009. 267 p.

. CONAB. Programa de Aquisição de Alimentos. Resultados das Ações da Conab em 2012.
MDA. Disponível em: <http://www.mda. gov.br/portal/saf/arquivos/view/alimenta-o-escolar/ publica-es/Apresenta\%E7\%E3o_PNAE_Geral. pdfPNAE/MDA > . Acesso em: 24 out. 2013.

CARNEIRO, M. J. Camponeses, agricultores e pluriatividade. Rio de Janeiro: Contra Capa, 1998.

ESQUERDO, V. F. de S. e BERGAMASCO, S. M. P. P. O processo de implantação da lei 11.947/2009 (PNAE) nos municípios do Circuito das Frutas-SP.In: V Simpósio sobre Reforma Agrária e Questões Rurais: políticas públicas e caminhos para o desenvolvimento. 2012. Araraquara. Anais... Araraquara: UNIARA, 2012. CD Rom.

FRANÇA, C. G., DEL GROSSI, M. E. e MARQUES, V. P. M. A. O Censo Agropecuário 2006 e a agricultura familiar no Brasil. Brasília: Nead/MDA, 2009.

GRISA, C. As políticas públicas para a agricultura familiar no Brasil: um ensaio a partir da abordagem cognitiva. Desenvolvimento em Debate. v. 1, n. 2, jan./abr. e maio/ago., p. 83-109, 2013.

., WESZ JUNIOR, V. J. e BUCHWEITZ, V. D. Revisitando o Pronaf: velhos questionamentos, novas interpretações. Revista de Economia e Sociologia Rural, Piracicaba-SP, v. 52, n. 2, abr.jun. p. 323-346, 2014.

., SCHMITT, C. J., MATTEI, L. F., MALUF, R. S. e LEITE, S. P. Contribuições do Programa de Aquisição de Alimentos à segurança alimentar e nutricional e à criação de mercados para a agricultura familiar. Agriculturas, v. 8, n. 3, p. 34-41, set. 2011.

GUANZIROLI, C. E. e CARDIM, S. E. de C. S. Novo Retrato da Agricultura Familiar. O Brasil redescoberto. Projeto de Cooperação Técnica Incra/Fao, Brasília: Incra/Fao, MDA, 2000.

GUANZIROLI, C. E. et al. Agricultura familiar e reforma agrária no século XXI. Rio de Janeiro: Garamond, 2001. $288 \mathrm{p}$.

INCRA/FAO. Perfil da agricultura familiar no Brasil: dossiê estatístico. Projeto UFT/BRA/036/BRA. Agosto de 1996.

KAGEYAMA, A. A., BERGAMASCO, S. M. P. P. e OLIVEIRA, J. T. A. Uma tipologia dos estabelecimentos agropecuários do Brasil a partir do censo de 2006. Revista de Economia e Sociologia Rural, Piracicaba-SP, v. 51, n. 1, p. 105-122, jan./mar. 2013.

KAGEYAMA, A. A. e BERGAMASCO, S. M. P. P. A estrutura da produção no campo em 1980. Revista Perspectiva, Unesp, v. 12/13, p. 55-72, 1990.

LABAT, J.L. F-C. e PEREZ, S.F.O. Mercado de TrabajoAgrario y Desarrollo Rural. Revista de 
EstudiosAgro-Sociales. Madrid (España). p. 89-118, 1994.

LAMARCHE, H. (Coord.). A agricultura familiar: comparação internacional. Tomo I. Trad. TIJIWA, A.M. N. Campinas: Ed. da Unicamp, 1993.

MALINA, L.L. Chamada Pública: instrumento legal de compra da agricultura familiar para a alimentação escolar. In: CORÁ, M.A.J. e BELIK, W. (Orgs.). Projeto NUTRE-SP: análise da inclusão da agricultura familiar na alimentação escolar no estado de São Paulo. São Paulo: Instituto Via Pública, 2012. p. 15-28.

MATTEI, L. Impactos do Pronaf: análise de indicadores. Brasília: MDA/NEAD, 2005.

MÜLLER, A. L. Programa de Aquisição de Alimentos da Agricultura Familiar e Programa Nacional de Alimentação Escolar. Brasília, 2010, 30 p. Relatório de Consultoria.

OTANI, M.N., FREDO, C.E. e RAMOS, R.C. Circuito das Frutas Paulista: caracterização socioeconômica. Informações Econômicas, SP, v. 42, n. 3, maio/jun. p. 50-64, 2012.

PREFEITURA MUNICIPAL DE JUNDIAÍ. Secretaria Municipal de Agricultura e Abastecimento. Emissão Mercosul: Produtos de Exportação - Circuito das Frutas - Turismo Rural. 2009. Disponível em: < http://www. selosefilatelia.com/PastaLancamentos09/016.html>. Acesso em: 12/05/2010.

SÃO PAULO (ESTADO). SECRETARIA DE AGRICULTURA E ABASTECIMENTO. COORDENADORIA DE ASSISTÊNCIA TÉCNICA INTEGRAL. INSTITUTO DE ECONOMIA AGRÍCOLA. Levantamento censitário de unidades de produção agrícola do Estado de São Paulo - LUPA 2007/2008. São Paulo: SAA/ CATI/IEA, 2008. Disponível em: < http://www.cati. sp.gov.br/projetolupa >. Acesso em: 15/09/2011.

SCHNEIDER, S. Agricultura familiar e pluriatividade. 1999. 500 f. Tese (Doutorado em Ciências Sociais) Programa de Pós-doutorado em Sociologia, Instituto de Filosofia e Ciências Humanas, UniversidadeFederal do Rio Grande do Sul, Porto Alegre, 1999.

SCHNEIDER, S., MATTEI, L. e CAZELLA, A. A. Histórico, caracterização e dinâmica recente do Pronaf - Programa Nacional de Fortalecimento da Agricultura Familiar. In: SCHNEIDER, S., SILVA, M. K. e MARQUES, P. E. M. (Org.). Políticas Públicas e Participação Social no Brasil Rural. Porto Alegre, p. 21-50, 2004.

SOUZA, L. B. B. Organizações da agricultura familiar no estado de São Paulo e sua experiência de fornecimento para o PNAE. p. 31-45. In: CORÁ, M. A. J. e BELIK, W. (Orgs.). Projeto NUTRE-SP: análise da inclusão da agricultura familiar na alimentação escolar no estado de São Paulo. São Paulo: Instituto Via Pública, 2012.

SPINELLI, M. A. S. e CANESQUI, A. M. O programa de alimentação escolar no estado de Mato Grosso: da centralização à descentralização (1979-1995). Rev. Nutr., v. 15, n. 1, p. 105-17, 2002.

TRICHES, R. M. Reconectando a produção ao consumo: a aquisição de gêneros alimentícios da agricultura familiar para o Programa de Alimentação Escolar. 2010. 297 f. Doutorado (Doutorado em Desenvolvimento Rural) - Programa de Pós-Graduação em Desenvolvimento Rural, Universidade Federal do Rio Grande do Sul, Porto Alegre, 2010.

TURPIN, M. E. A Alimentação escolar como vetor de desenvolvimento local e garantia da segurança alimentar. 2008. Dissertação (Mestrado em Desenvolvimento Econômico) - Área de Concentração em Economia Agrícola e Agrária. Universidade Estadual de Campinas; Campinas, 2008.

VEIGA, J. E. da. Delimitando a agricultura familiar. Reforma Agrária, v. 25, n. 2 e 3, p. 128-141, mai./dez. 1995.

WANDERLEY, M. de N. B. Raízes históricas do campesinato brasileiro. In: TEDESCO, J. C. (Org). Agricultura familiar: realidades e perspectivas. Passo Fundo: EDIUPF, 1999. 